\title{
Gratitude Education in Medical University
}

\author{
Jinguo Wang \\ Department of Urology \\ The First Hospital of Jilin University \\ Changchun, China \\ wangjinguolily@163.com
}

\author{
Na Wang *(corresponding author) \\ Department of Anesthesiology \\ The First Hospital of Jilin University \\ Changchun, China \\ wangna080613@163.com
}

\begin{abstract}
The aim of this study is to improve the humanity quality of medical students by Facing the reality of deterioration of the doctor-patient relationship, teachers should improve the external conditions, deep into the medical students, pay attention to the cultivation of the gratitude mentality, help them to improve the awareness of thanksgiving and work with a grateful attitude to learn. It improves the humanity quality and gratitude mentality of medical students. The combination of the gratitude mentality and humanism is the goal and orientation for the development of medical sciences.
\end{abstract}

\section{Keywords-Gratitude education, Medical students, Education}

\section{INTRODUCTION}

Thanksgiving education is an important part of moral education; educators use certain education methods and means, on the basis of certain Thanksgiving education content, the knowledge of the implementation of medical students, knowledge, kindness and mercy of humanistic education. The individual gratitude and gratitude emotion is the premise and foundation, and gratitude and the resolve to return favors behavior is the key. In medical colleges and universities, medical science and technology of the rapid development of the new situation of university medical students Thanksgiving education put forward new requirements, according to the characteristics of the medical students themselves, draw lessons from Chinese and western traditional Thanksgiving thought resources, by creating the atmosphere of Thanksgiving education socialization, advancing the scientific school gratitude education, promote the medical students practice gratitude consciousness.

\section{CUSTOMER RELATIONSHIP MANAGEMENT IN HOSPITAL}

Customer relationship management (CRM), as a management phenomenon already exist, however, as a kind of mature management idea and management technology is applied to hospital management, is the rise in recent years. American marketing association defines CRM simple as: to assist enterprises to establish good relationship with customers, make both of us benefit management mode type.

A. The individual gratitude emotion is the premise and foundation, and the behaviors of returning favors for gratitude feelings are the key.

Gratitude is the natural, social, and others to their favor and heartfelt recognition, and sincere return cognition, emotion and behavior. Gratitude education of medical students in medical students has a positive role in the process of growing up. In Chinese traditional culture, Thanksgiving is a virtue. Medical students should not only study hard medical knowledge, master of medical talents, but also set up the noble moral goal, cultivating their gratitude consciousness, the noble medical ethics principles and norms as engaged in professional code of conduct in the future. Medical colleges should through the perfect Thanksgiving education evaluation system, the gratitude education standardization, specific and institutionalization, prompt medical students self-discipline and heteronomy organically, realize the knowledge and the highly unified, and in the process of implementation of the medical students' Thanksgiving education, improving the ideological and moral state of medical students [1].

With the development of the reform and opening up, the college students' moral accomplishment is generally healthy positive, many college students to value their own learning opportunities, and through its own action and effort to give rewards to the parents and society to help. However, with the development of society and economic, the one-child in social population, more and more possession, compared with previous people, in such aspects as background and education experience they have great differences. And society is in transition period, the market factors lead to all sorts of prevailing utilitarian ideas, some of these negative factors also led to the college students are worrying, such as moral overall landslide, one-upmanship money consumption between classmates, endlessly to parents claim, etc. They give parents and others to help for granted all the family love, friendship and love between teachers and students, such as lack of gratitude consciousness so as to show some degree of mental "vacuum". To this, in addition to the student's own factors, family and family factor is also to be reckoned with, such as a lot of parents to children's study, no matter do anything around the child's academic performance, think it's all for the sake of famous university, finally find a good job, but for the child's personality and emotional cultivation are completely ignored, this is not conducive to the harmonious relationship between people health [2].

And laws of the increasingly fierce competition in the society to a certain extent also polluted the relationships between people, between people to prevent heart to strengthen, the selfless outstretched hand. Many college students lack of gratitude consciousness of worry, they will help social and family as a well-deserved, deep problem that is worth our reflection. Indifferent in the face of these phenomena, we can't, although these phenomena is not the mainstream of the society, 
but it can't underestimate the influence of the harm inevitably leads to the individual quality of selfishness, socially human indifference and lack of moral .Corresponding to the phenomenon of college students' lack of gratitude is vigorous in the colleges and universities to carry out college students' moral education work, is generally ignored the moral education is an important content of gratitude education [3]. Although in recent years some universities have gradually realize the importance of gratitude education, also made some exploration on the practice, but the gratitude education concept, goal setting, curriculum, education method and practice on the way to still exist many problems, education effect is not ideal. The research and evaluation system is more a lack of systematic research.

\section{B. According to the career characteristics of the medical students and shortage of gratitude emotion in medical students, gratitude education is very necessary.}

Medical students are a special group, their particularity from special career in the future. They work in the future is directly related to the quality of individual life, family and sorrows, social prosperity and stability, as well as peace and progress of mankind. Their gratitude quality situation will affect their professional moral level, will determine the results of their behavior and behavior, is directly related to people's physical and mental health and life safety was based on the realistic background, this paper tries to the problems existing in the medical students' Thanksgiving education to conduct a comprehensive in-depth analysis, and put forward countermeasures according to the problem, not only can provide reference for medical colleges and universities of Thanksgiving education, but also for correct concept of gratitude to guide medical students, to construct the harmonious medical industry also has the profound significance.

Today, we are in a new period of the construction of the socialist market economy, market economy is legal economy, regulate the economy. But even the market itself trading activities, in addition to market regulation and government regulation, the regulation of moral force is also essential. As for the social life of the trading area, the more need to moral regulation. Gratitude is one of the moral powers. People have a Thanksgiving heart, people, people and nature, between people and society will become more harmonious and more cordial. People also can because of the existence of psychological Thanksgiving and be happy and healthy, as the students really learned to Thanksgiving, can be more understanding and tolerance, more motivated to learn, to live more happiness. Thanksgiving is not a simple kindness, but for a measure of the value of life, a grateful person must be a man with a healthy personality. As colleges and universities should not only take the need of cultivating advanced professional and technical personnel, more should develop with a social conscience, kindness, know how to be qualified socialist citizens. Medical students are a special group, their particularity from special career in the future. Medical students in the future of the service object is a person, is the patient, the professional ethics is directly related to people's physical and mental health and life safety [4]. The theory of college students' gratitude and
Thanksgiving education for a large number of related research, but for this special group of vocational medical students of gratitude and Thanksgiving education study is less; some are involved, but lack of the analysis of the system, to its disadvantages, and to explore its internal reasons. Therefore, in the period of social transformation, how to medical students to effectively implement the "emotional education", cultivating "Thanksgiving culture", make the medical students learn to respect life, gratitude to others and the society, help to cultivate medical students noble medical ethics, provide a reference for medical colleges and universities of Thanksgiving education, to build a harmonious medical industry, the construction of a harmonious society has profound significance.

The domestic research most remain in the summary of practical experience, on the basis of part of the theoretical basis for the Thanksgiving education to explore, mainly focus on macro operating part of the college students' Thanksgiving education practice. At the same time practice research is not comprehensive, system, focuses on the study of macro strategy, the study of specific operation. The goal of the college students' Thanksgiving education is not clear, the contents of the college students' Thanksgiving education to explore deeply enough. Especially for medical students' this special group, how to implement the Thanksgiving education, as well as the effectiveness of the Thanksgiving education research, Thanksgiving education evaluation system research is not enough, remains to be further mining, it also offers I research the topic space available for play.

Method refers to the people in order to achieve the purpose of to know the world and transform the world, in the process of scientific research methods, ways and techniques adopted by the general. This article mainly USES the research method is as follows: summary: from the grasp of the relevant literature to sum up, find out the common parts of the key problems need to be solved to find, and advances some corresponding countermeasures. Comparison analysis: in this paper, guided by the Marxism, applying the viewpoints of dialectical materialism and historical materialism analysis comparing medical students and other professional college students' Thanksgiving education, through the analysis and comparison, absorbing, to clear the particularity of medical students' Thanksgiving education, implementation of gratitude education of medical students provides the beneficial reference. In combination with theory and actual: use the maximal stand, viewpoint and method, combining theory study and practice, through the way of field survey, interview, in medical college as an example, understand the current contradictions and problems of the medical students' Thanksgiving education, to strengthen the perceptual knowledge of research objects, research accumulation of first-hand information for the selected topic. Will draw lessons from foreign experience combined with China's actual, to improve medical students' Thanksgiving education initiatives.

\section{According to the career characteristics of the medical students and shortage of gratitude emotion in medical students, gratitude education is very necessary.}

From the point of the existing research results, Thanksgiving education for college students and gratitude 
education of primary and middle school students study more, but few studies involving the gratitude education of medical students. This article will from conforms to the medical students' own characteristics, in view of the education object, education mode and the particularity of education content, improve the medical students' Thanksgiving education measures, in order to achieve the innovation of research Angle.

In the current research results, however, the status and countermeasures of college students gratitude education research is more, but of the construction of the evaluation index system for gratitude education rarely involved. This article attempts to discuss from the path of implementation of Thanksgiving education Thanksgiving education of the construction of the evaluation index system, in order to achieve the innovation of research. Based on the epistemology of maximal as a guide, follow the rules of human knowledge, actively absorb the other, on the basis of research results, attempt to medical students the related content of Thanksgiving education, and put forward the gratitude education effective evaluation system, in order to reflect the original work.

Above is to "Thanksgiving" connotation explanation, the Thanksgiving education is actually educators use certain education methods and means, on the basis of certain Thanksgiving education content, the knowledge well, know well of the implementation of education, kindness and mercy of humanistic education. It's a kind of "feeling emotional education", "good, good moral education", "humanity awakens humanity education". Can say, Thanksgiving ideas are not the natural endowment, but needs to be acquired education for guidance and inspiration, through education, can help people to find the good life, to face the society with a grateful eyes, and a sense of gratitude and responsibility for the actual gratitude. From this point on, Thanksgiving education is not merely a kind of moral education; education is also a kind of human emotions. Can say, Thanksgiving education contains the ultimate concern of human nature that is the essence of it is in order to improve people's lives, make it's become richer and more valuable. In general, there are three levels of gratitude, the first is cognitive level, namely through their own understanding and thinking, in the heart to produce a cognitive and licensing. The second is the emotional level, that is, the individual on the basis of recognition of gratitude, to produce a pleasant emotion, which translates into a desire to the kindness of inner impulse [5]. Third is the practice level, that is, on the basis of the cognitive and emotional level, converts gratitude to the concrete action, will implement the grateful thoughts and feelings, form the good habit dedicated.

Fear of life view refers to the people to respect, care and respect for life, maintenance system to recognize and value judgment, refers to the relationship between people in dealing with all the associated with life, namely, people, people and society, the relationship between human and nature with respect to hold in the course of life, cherish life, care for life value judgment principle, the basic stand, viewpoint and method. The concept is especially in the medical practice of early man.

Thanksgiving education for medical students, is to let students understand myself why gratitude, who is the object of gratitude, gratitude what thought for themselves and others, social significance, study medicine is not only to learn medical skill, but also learn medical ethics. Rules, practicing medicine treat patients, and put themselves in their patients' shoes, the education of medical ethics education is the studied medicine from that moment start. Medical students have the gratitude and gratitude emotions, to use equality view of every life, learn to respect life, love life, gratitude to others and the society. When the medical students set up the fear of life, peopleoriented service concept, and takes action in the later work, will improve the doctor-patient relationship and build a harmonious society and also a good drive and promoting role.

Higher medical education is an important part of higher education, shoulders the training medical talents, maintain and promote human health mission. In the face of the needs of the 21st century, is the consensus of the world, with comprehensive qualities and comprehensive development of a doctor, can be called qualified medical talents. Therefore, China's higher medical colleges and universities should not only pay attention to cultivate the students' professional knowledge, more want to cultivate the students' moral quality, it is the core of the medical colleges and universities personnel training task, also is the key to college life and development force.

\section{CONCLUSION}

Implementation of Thanksgiving education among medical students, and to conform to the medical students' own characteristics, in view of the education object, education mode and the particularity of education content. To improve medical students' Thanksgiving education initiatives, is to draw lessons from Chinese and western traditional Thanksgiving resources, actively build Thanksgiving culture; build the entire social good Thanksgiving atmosphere. To follow the teachers' leading role and students' main body effect of combining the education teaching rule, strengthen the medical students' school gratitude education. According to the characteristics of medical students, the improvement of gratitude education is teaching content and methods. Strengthen the course construction of doctor-patient relationship, pay attention to practice before the education link, strengthen the practice of doctor-patient communication skills, and carry out various forms of education to strengthen course effect. Play a model role, strengthening the construction of teaching staff, build sweet gratitude campus culture. Advocate medical multiply improve self-cultivation, to form a good habit of gratitude. Perfect Thanksgiving education evaluation system, the gratitude education institutionalization, standardization and concretization, makes the discipline of medical students and gratitude assessment system of heteronomy organically, realize the knowledge and the highly unified, and show the positive value of gratitude education

\section{REFERENCES}

[1] Wen Jiabao. Report on the work of the government delivered at the Fourth Session of the Eleventh National People's Congress. http://news.sina.com.cn/c/2011-03- 05/105922057880.shtml . 
[2] Liu Ke. "Strengthening and Promoting Service, Building a Harmonious Society". Journal of Xi'’an University of Posts and Telecommunications . 2009

[3] He Hongxia."On University Volunteer Community Service". Journal of Shanxi Youth Vocational College . 2009
[4] Chen Lingping, Lingxiqin. Developing College Students' Service Consciousness to Serve the Development of Local Economy: Based on Colleges in Guangxi [A].

[5] Shuguang Liu, Bo Dong, Yan Sun. The Method and Practice of University Students' Creative Education [A]. 